\title{
ANIMAL MODELS AS AN EXPERIMENTAL TOOL IN DIABETES RESEARCH
}

\section{Naveen Kumar T}

Associate professor, Department of Pharmacology, Apollo Institute of Medical Science \& research, Jubilee Hills, Hyderabad, A.P., India

*Corresponding Author's Email ID; doctornaveen1@rediffmail.com

\begin{abstract}
Objective: The review give an overview on the animal models, their short comings and the precautions required for each technique to the investigators in diabetes research.

Material and Methods: Data was collected from journals,electronic library, standard text books of experimental pharmacology analysed and relevant data was taken

Results and Conclusion: The disease remains incurable and can be only controlled by discovering new drugs choosing various experimental diabetes models to minimise the risk of diabetic complications.

Key words: Diabetes mellitus, Alloxan, Streptozotocin, Animal models.
\end{abstract}

\section{INTRODUCTION}

Type 2 diabetes is a complex disorder presently affecting people worldwide causing serious socio-economic problems. The existence of experimental animal model of a disease aids not only the understanding of the pathophysiology of such disease, but also the development of drugs for its treatment. According to the World Health Organization (WHO), there are approximately 160,000 diabetics worldwide, the number of diabetics has double in the last few years and is expected to double once again in the year 2025 . Due to its high prevalence and potential deleterious effect on a patient physical and psychological state, diabetes is a major medical concern .Over the years, several animal models have been developed for studying diabetes mellitus or testing anti-diabetic agents. These models include chemical, surgical (pancreatectomy) and genetic manipulations in several animal species to induce diabetes mellitus. The selection of these models to use for investigating the antidiabetic properties of a new compound may be a very difficult task especially for young researchers and at times leading to misinterpretation of data or even wrong conclusions. The selections of inappropriate animal models have been identified as one of the common problem associated with ethnobotanical research. The aim of the present review is to piece together all the various experimental models developed for studying diabetes mellitus, assess the merits and demerits of each model and highlight the precautions needed to avoid erroneous results during the applications of these models.

The currently existing animal models in diabetic researchcan be divided in to 2 main type :

Insulin dependent diabetes mellitus (IDDM ) and Non insulin dependent diabetes mellitus (NIDDM).

\section{Animal Models}

Insulin dependent diabetes mellitus -IDDM are 3 types which includes Chemical induced, surgically induced and Genetic induced.

Non insulin dependent diabetes mellitus - NIDDM are mainly 3 types which includes(1) Chemically induced,
(2) Genetic models - ob/ob,db/db mice, KK, KK/A ${ }^{\mathrm{y}}$ mice, New Zealand obese mice, ZFR, ZDR, Gk rat, Torri rat. (3) Sand rat (environmental component).

\section{Chemically induced Diabetes}

Most commonly used model for Insulin dependent diabetes mellitus. The chemicals used are Alloxan and Steptozocinwhich cause Beta cell damage.

Alloxan model of diabetes mellitus: It is a well- known diabetogenic agent widely used to induce Type 11 diabetes in animals ${ }^{1}$.Alloxan is a urea derivative which causes selective necrosis of the pancreatic islet $\beta$-cells. Alloxan and its reduction product dialuric acid establish a redox cycle with the formation of superoxide radicals. These radicals undergo dismutation to hydrogen peroxide. Thereafter, highly reactive hydroxyl radicals are formed by fenton reaction. The action of reactive oxygen species with a simultaneous massive increase in cytosolic calcium concentration causes rapid destruction of betacells ${ }^{2}$. It is used to produce experimental diabetes in animals such as rabbits, rats, mice and dogs. With this agent, it is possible to produce different grades of severity of the disease by varying the dose of alloxanused.Doseused for Rat -65 $\mathrm{mg} / \mathrm{kg}$ i.v and $150 \mathrm{mg} / \mathrm{kg}$ i.p/sc , Rabbit $-150 \mathrm{mg} / \mathrm{kg}$ i.v , Beagle dog -60mg/kg i.v, Monkey -65to $200 \mathrm{mg} / \mathrm{kg}$ i.v.Alloxandiabetogenic action exhibits triphasic response ie within 2 hours after administration , 8 hours after administration and 24 hours after administration. Because of its low stability, relatively very shorter half-life (less than $1 \mathrm{~min}$ ) and acidic nature of solution, intravenous route of administration of Alloxan is preferred. Thehypoglycaemic phase may be quite severe and therefore alloxan should not be given to fasted animals. The alloxan treated animals exhibit severe hyperglycaemia, glucosuria, hyperlipidaemia, polyphagia, polydypsia and other symptoms of uncontrolled diabetes and do also develop various complications such as neuropathy, cardiomyopathy, well-marked retinopathy and others. Alloxan is disadvantageous as the percentage incidence of diabetes is quite variable and is not 
proportionately related to increasing doses of alloxan ${ }^{3}$.Further, the incidence of ketosis and resulting mortality is high. The reversal of hyperglycaemia due to pancreatic regeneration is early and common in case of alloxan treated animals. Because of these limitations, alloxan is now almost replaced by streptozotocin for induction of diabetes in laboratory animals.

Streptozotocin model of diabetismellitus:Streptozotocin is a synthetic nitrosoureidoglucopyranose derivative isolated from fermentations of streptomycesachromogenes. Itsnitrosourea moiety is responsible for beta celltoxicity, while deoxyglucose moiety facilitatestransport across the cell membrane. Like alloxan, theinvolvement of free radicals generation and resultingalteration of endogenous scavengers of these reactivespecies have been reported in Streptozotocindiabetogenecity ${ }^{4}$.

Further, streptozotocincausing alkylation or breakage of DNAstrands and a consequent increase in the activity ofpoly-ADP-ribose synthetase, an enzyme depletingNAD in beta cells finally leading to energydeprivation and death of beta cells is reported. As NAD is an antioxidant which exerts protective effect on the cytotoxic action of Streptozotocin by scavenging free radicals and causes only minor damage to pancreatic beta cell mass producing type 2 diabetis.

Single dose of Streptozotocin in sterile citrate buffer (e.g. $\mathrm{pH} 4.50 .1 \mathrm{M})$ may be used: mice $150 \mathrm{mg} / \mathrm{kg}$, rats 80 $\mathrm{mg} / \mathrm{kg}$, dog $15 \mathrm{mg} / \mathrm{kg}$ administered intraperitoneally. Guinea pigs and rabbits are resistant to streptozotocin. Diabetes develops gradually and may be assessed after a few days, usually four days for mice and seven days for rats. Usually, a serum glucose level of about $180-500 \mathrm{mg} / \mathrm{dl}$ indicates the induction of diabetes mellitus.Sometimes diabetic animals are maintained on insulin if the experiments are not to commence immediately to prevent the animals' dead'.

Streptozotocin is the most commonly used drugfor induction of diabetes in animal models 6 . There are some disadvantages to its use in chronic experiments, especiallyspontaneous recovery from high blood glucose levels by the development of functioning insulinoma and high incidence of kidney and liver tumours. These problems are due strongly to oncogenic action of Streptozotocin ${ }^{7}$.Streptozotocin is a preferred agent to induce experimental diabetes since it has some advantages over alloxan such as, relatively longer half-life (15 min), sustained hyperglycaemia for longer duration and the development of well characterized diabetic complications with fewer incidences of ketosis as well as mortality. Alloxan andstreptozotocin diabetic animals are most widely used for screening the compounds including natural products for their insulinomimetic,insulinotropic and other hypoglycaemic/ antihyperglycaemic activities.

Combination of high fat or fructose diet plus steptozotocin cause beta cell damageleading to progressionof insulin resistance to type- 2 diabetes in out bred animals.

\section{Surgical model of diabetis mellitus}

Another technique used to induce diabetes is complete removal of the pancreas (pancreatectomy). Few researchers have employed this model to explore effects of natural products with animal species such as rats, pigs, dogs and primates ${ }^{8}$.Limitation to this technique include high level of technical expertise ,adequate surgical room environment, major surgery, high risk of animal infection, adequate post-operative analgesia, antibiotic administration, supplementation with pancreatic enzymes to prevent malabsorption and loss of pancreatic counter regulatory response to hypoglycemia. More recently, partial pancreatectomy has been employed, but large resection (more than $80 \%$ in rats) is required to obtain mild to moderate hyperglycemia. In this case, small additional resection can result in significant hypoinsulinemia ${ }^{9}$. This experimental design permits to evaluate if the compound has some effect on insulin resistance and secretion of insulin.

\section{Genetic models of Insulin dependent diabetes mellitus (IDDM)}

The non obese mutant mouse has been developed BY Makino and colleagues in shionogi research laboratories in japan in 1980. The non obese mutant mouse (Akita mouse) has been derived from the colony of C57 BL/6 (B6) now commercially available for research at Jackson Laboratory, Bar Harbor. The Ins 2 gene is the mouse homologue of human preproinsulin gene. Mice possess another active insulin gene, Ins I, which lacks an intron present in the Cpolypeptide-encoding region. The Akita (Ins2Akita) spontaneous mutation (commonly referred as Mody) is an autosomal dominant mutation in the insulin II gene (Ins2)60. Ins2Akita mutation disrupts normal insulin processing and causes a failure in secretion of mature insulin, which results in early development of hyperglycaemia. It is characterized by hyperglycaemia, hypoinsulinaemia, polydipsia and polyuria, beginning around 3-4 wk of age. Obesity or insulitis does not accompany diabetes. These mutant mice respond well to exogenously administered insulin. The mice with reduced beta cell mass and absence of beta cell autoimmunity serve as an excellent substitute for mice made diabetic by treatment with certain chemical diabetogens for islet transplantation studies ${ }^{10}$.

Genetic models for Non-Insulin dependent diabetes mellitus (NIDDM ${ }^{11}$. Example is the spontaneously diabetic Goto-Kakizaki rat which is a genetic lean model of type 11 diabetes originating from selective breeding over many generations of glucose-intolerant nondiabeticwistar rats 12 . Regarding type1 diabetes models)

\section{Spontaneously develop diabetic rats:}

Thesemodels permit the evaluation of the effect of a natural product in an animal without the interference of the side effects induced by chemical drugs like alloxan and STZ reported above. Several recent publications summarized the major advances in this field, the mouse typically presents hyperglycemia between 12 and 30 weeks of age, whereas in $\mathrm{BB}$ rats it occurs around 12 weeks of age. One great advantage of these models is that they can be employed as model of atherosclerosis which represents the long term complication of diabetes mellitus and can be tested against several natural products ${ }^{13}$. 


\section{Zucker fat rat (ZFR)}

These rats resulting from the mutation on chromosome no 5.Inherited as autosomal resistant type. Defect in signaling mechanism of Leptin receptorsin hypothalamus is responsible for development of diabetes.Contain sturdy beta cellcapable of maintain high insulin secretion to counter the insulin resistance. This model is used as model for obesity, Non-Insulindependent diabetesmellitus associatedwith typeIV hyperlipidaemia, hypertension ,screening of insulin sensitizers,incretinomimetics and anti-obesity drugs.

\section{Obese Rhesus Monkey}

It is a non rodent model for diabetis.Adlibitium lab diet is used for this model to develop diabetes.The animal develop obesity, insulin resistanace and hyperinsulinaemia.This model is used for screening of insulin sensitizers.

Non obese genetic models: The models are GK rat and Torri rat

GK rat : GotoKakisakirat.These rats shows defective development of pancreas due to inadequate production of PGF(pancreatic growth factor) during its foetallife. The rats shows fasting hyperglycemia.This model is used to studythe relation between reduced $\beta$ cell mass and occurrence of diabetis and diabetic complications like diabetic nephropathy.

\section{Torri rat}

Developed by Torri Pharmaceuticals, Japan.These rats shows-Hypoinsulinaemia $\quad-\quad$ fibrosis in pancreas,hyperglycemia and glucose intolerance .This model is useful for study on diabetic complications like cataract,retinopathy and retinal detachment.

\section{REFERENCES}

1.Viana GS, Medeiros AC, Lacerda AM, Leal LK, Vale TG, Matos FJ. Hypoglycemic and anti-lipemic effects of the aqueous extract from Cissussicyoides. BMC Pharmacology.2004; 8: 4-9.

2.Szkudelski T. The mechanism of alloxan and streptozotocin action on B cells of the rat pancreas. Physiology Res.2001; 50:536-546.

3.Battell ML, Yuen VG, Verma S, McNeil JH. Other models of type 1 diabetes. In: McNeil JH, editor.Experimental models of diabetes. Florida, USA: CRC Press LLC; 1999 .p. 219-29.

4. Junod A, Lambert AE, Stauffacher W, Renold AE. Diabetogenic action of streptozotocin.ProcsocExpBiol Med.1967; $126: 201-5$.

5. Williamson EM, Okpoko DT, Evans FJ . Pharmacological methods in phytotherapy research. John Wiley and sons, Inc. Third Avenue, New York, USA.ISBN 047194216 2.1996. p. 155-67.

6. Balamurugan AN, Miyamoto M., Wang W, Inoue K. and Tabata Y. Streptozotocin (STZ) used to induce diabetes in animal models.2003; 26: 102-03.

7. Kazumi T, Yoshino G, Fujii S, Baba S. Tumorigenic action of streptozotocin on the pancrease and kidney in male wistar rats. Cancer Res.1978; 38: 2144- 47 .
Genetically engineered diabetic mice

In this case, rodents may be produced to over (transgenic) or under (knockout)-express proteins thought to play a key part in glucose metabolism.Although significant advances in this field have arisen in recent years, especially with the advent of transgenic mice, there have been no studies carried out involving natural products on these models. Certainly, the high cost restricts their study in sophisticated protocols which explore mechanism of potential therapeutic agents that either stimulates pancreatic $\beta$-cell death. Insulin dependent diabetes mellitus (IDDM) can be developed by inserting into mice unique viral protein which then express as a self-antigen in the pancreatic islets of langerhans. Autoimmune mediated destruction of beta cells of the islets of langerhans leads to insulin dependent diabetes mellitus (IDDM).

\section{SUMMARY AND CONCLUSION}

Many of the animal models described apparently share similar characteristic features of type 2 diabetes and have allowed experimentation that would be impossible in humans. None of the known single species is exactly equivalent to human diabetes, but each model act as essential tool for investigating genetic, endocrine, metabolic, morphologic changes and underlying aetiopathogenic mechanisms that could also operate during the evolution of type 2 diabetes in humans. Hence, care must be taken in interpretation and extrapolation of the results obtained from these animal models to humans. In the screening programme of anti-diabetic compounds, it is particularly important to note that some animal models are better suited to screen particular class of anti-diabetic compounds.

8. Choi SB, Park CH, Choi MK, Jun DW, Park S. Improvement of insulin resistance and insulin secreation by water extracts of Cordicepsmilitaris, phellinuslinteus and paecilomycetenuipesin 90\% pancreatectomized rats. J. Biotech. and Biochem.2004; 68: 2257- 64.

9. Masiello P. Animal models of type11 diabetes with reduced pancreatic $\beta$-cell mass. The international Journal of Biochemistry and Cell Biology.2006; 38:873-93.

10. Mathews CE, Langley SH, Leiter EH. New mouse model to study islet transplantation in insulin dependent diabetes mellitus. Transplantation. 2002; 2 : 1333-6.

11. Masiello P. Animal models of type 11 diabetes with reduced pancreatic $\beta$-cell mass. The international Journal of Biochemistry and Cell Biology.2006; 38:873-93.

12. Chen D, Wang MW .Development and application of rodent models for type-11 diabetes.Diabetes, Obesity and metabolism.2005; 7: 307-17.

13. Wu KK, Huan Y. Diabetic atherosclerosis mouse models. Atherosclerosis.2007; 191: 241-49. 